\title{
Impact of ocean warming and acidification on the behaviour of two co-occurring gadid species, Boreogadus saida and Gadus morhua, from Svalbard
}

\author{
Matthias Schmidt ${ }^{1,2}$, Gabriele Gerlach ${ }^{3}$, Elettra Leo ${ }^{1,2}{ }^{,}$Kristina Lore Kunz $^{1,2}$, \\ Steffen Swoboda ${ }^{1}$, Hans-Otto Pörtner ${ }^{1,2}$, Christian Bock ${ }^{1}$, Daniela Storch ${ }^{1, *}$ \\ ${ }^{1}$ Alfred Wegener Institute, Helmholtz Centre for Polar and Marine Research, Section Integrative Ecophysiology, \\ Am Handelshafen 12, 27570 Bremerhaven, Germany \\ ${ }^{2}$ University of Bremen, Fachbereich 2, NW 2 / Leobener Strasse, 28359 Bremen, Germany \\ ${ }^{3}$ Carl von Ossietzky University Oldenburg, Institute for Biology, Group Biodiversity and Evolution of Animals, \\ Carl von Ossietzky Str. 9-11, 26111 Oldenburg, Germany
}

\begin{abstract}
Ocean acidification induces strong behavioural alterations in marine fish as a consequence of acid-base regulatory processes in response to increasing environmental $\mathrm{CO}_{2}$ partial pressure. While these changes have been investigated in tropical and temperate fish species, nothing is known about behavioural effects on polar species. In particular, fishes of the Arctic Ocean will experience much greater acidification and warming than temperate or tropical species. Also, possible interactions of ocean warming and acidification are still understudied. Here we analysed the combined effects of warming and acidification on behavioural patterns of 2 fish species co-occurring around Svalbard, viz. polar cod Boreogadus saida and Atlantic cod Gadus morhua. We found a significant temperature effect on the spontaneous activity of $B$. saida, but not of G. morhua. Environmental $\mathrm{CO}_{2}$ did not significantly influence activity of either species. In contrast, behavioural laterality of $B$. saida was affected by $\mathrm{CO}_{2}$ but not by temperature. Behavioural laterality of G. morhua was not affected by temperature or $\mathrm{CO}_{2}$; however, in this species, a possible temperature dependency of $\mathrm{CO}_{2}$ effects on relative laterality may have been missed due to sample size restrictions. This study indicates that fish in polar ecosystems may undergo some, albeit less intense, behavioural disturbances under ocean acidification and in combination with ocean warming than observed in tropical species. It further accentuates species-specific differences in vulnerability.
\end{abstract}

KEY WORDS: Ocean acidification $\cdot$ Climate change $\cdot$ Fish behaviour $\cdot$ Laterality $\cdot$ Activity $\cdot$ Polar habitat $\cdot$ Atlantic cod $\cdot$ Polar cod

\section{INTRODUCTION}

Ocean acidification $(\mathrm{OA})$, i.e. the perturbation of seawater carbonate chemistry by accumulating $\mathrm{CO}_{2}$, has the potential to strongly alter the behaviour of various marine teleosts and elasmobranchs, affecting for example their activity, boldness, predator avoidance, learning and behavioural laterality, and interfering with their sensory processes (Heuer \& Grosell
2014). While behavioural alterations have mostly been observed under acute exposure to increased $\mathrm{CO}_{2}$ partial pressure $\left(\mathrm{pCO}_{2}\right)$, there also appears to be a species-specific potential to adapt behaviour across generations (Miller et al. 2012, Allan et al. 2014, Munday et al. 2014, Welch et al. 2014). However, OA develops in parallel to ocean warming (OW), but to date, interactive effects of OA and OW on the behaviour of teleosts remain understudied and have been 
analysed only in a few tropical species (Nowicki et al. 2012, Domenici et al. 2014, Ferrari et al. 2015). In coldadapted fish species, OA-induced behavioural changes have not been assessed, although the polar ocean of the northern hemisphere is expected to experience the greatest changes in both temperature and $\mathrm{pCO}_{2}$ induced acidification in the near future (IPCC 2013).

Here we analysed the combined effects of OA (as projected for the year 2100) and temperature on spontaneous activity and behavioural laterality of 2 co-occurring teleost species from Svalbard, Norway. These types of behaviour have been shown to be affected by $\mathrm{CO}_{2}$ in tropical (activity and laterality) and temperate (laterality) fish species. $\mathrm{CO}_{2}$-induced effects on activity are species dependent, with activity being either increased or reduced by a predicted rise in $\mathrm{CO}_{2}$ (Munday et al. 2010, 2013, 2014, Cripps et al. 2011, Nowicki et al. 2012). Behavioural lateralization is defined as the side preference of an animal conducting a certain task (e.g. 'handedness') or, in this study, the tendency to turn to one side at the end of an experimental runway (Domenici et al. 2012). Earlier studies observed a reduction in the behavioural laterality of tropical and temperate fish species after acclimation to OA scenarios (Domenici et al. 2012, 2014, Jutfelt et al. 2013) with the exception of temperate Atlantic cod Gadus morhua and the temperate wrasse Ctenolabrus rupestris (Jutfelt \& Hedgärde 2015, Sundin \& Jutfelt 2016).

Increased spontaneous activity can lead to higher energetic demands, requiring more food uptake, which can subsequently lead to greater exposure to predators (Munday et al. 2013). Conversely, an increase in activity could be the consequence of reduced foraging success or increased energetic demand leading to intensified foraging behaviour to fill this energetic gap (Cripps et al. 2011). The potential effects of behavioural lateralization on animal fitness are not fully resolved. Lateralized behaviour reflects functional asymmetry of the brain, where one brain hemisphere specializes in conducting a certain task. Specialization may be useful to increase the speed of sensory processing when several different stimuli must be analysed simultaneously (Rogers et al. 2004). This is especially important in fish, such as Gadidae, that possess lateral eyes and no mobile neck, so that each eye (and thus each brain hemisphere) perceives an almost entirely different set of visual information (Vallortigara \& Rogers 2005). Furthermore, fish lack the corpus callosum that accelerates information transfer between brain hemispheres in placental mammals (Dadda et al. 2009). Dadda et al. (2010) found a correlation between the degree of behavioural lateralization and escape performance in teleost prey fish. As a trade-off, non-lateralized animals performed better at cognitive tasks than lateralized fish when relevant similar stimuli occurred simultaneously on both sides of the body (Dadda et al. 2009). While these findings explain why nonlateralized animals are also commonly found in the wild, they complicate prediction of ecological consequences caused by changes in laterality on a population level. Here, we interpret a change in behavioural laterality as a proxy for disturbance in nervous system functioning, in similar ways as reported by Domenici et al. (2012).

The polar cod Boreogadus saida has a circumpolar distribution in Arctic and subarctic waters and is considered a key species in the Arctic ecosystem (Hop \& Gjøsæter 2013). The Atlantic cod Gadus morhua is a temperate fish species which has shifted its distribution farther north with recent warming (Sundby \& Nakken 2008, Drinkwater 2009). At present, the distribution areas of B. saida and G. morhua overlap for most of the year in the coastal waters around Svalbard, where sea surface temperature fluctuates between $-1.8^{\circ} \mathrm{C}$ in winter and up to $8^{\circ} \mathrm{C}$ in summer (Renaud et al. 2012, Beierlein et al. 2015). The surface water temperature of this area is predicted to increase further by $2.5^{\circ} \mathrm{C}$ until the year 2100 according to the Representative Concentration Pathway (RCP) 8.5 scenario (IPCC 2013). The consequences of further temperature-driven northward migration of G. morhua and its interaction with $B$. saida on the Arctic ecosystem are unknown, especially as simultaneous OA might alter the usual behaviour of each species. We sought to document the species-specific vulnerability of the behaviour of both $B$. saida and $G$. morhua in response to combined OW and OA. We therefore incubated B. saida and G. morhua for $6 \mathrm{wk}$ under present-day and future $\mathrm{pCO}_{2}$, with the latter being set close to the maximum $\mathrm{pCO}_{2}$ value projected by RCP 8.5 for the year 2100 (IPCC 2013). Animals were incubated at 4 different temperatures, between 0 and $8^{\circ} \mathrm{C}$ for $B$. saida and between 3 and $16^{\circ} \mathrm{C}$ for $G$. morhua, to cover a broad overlapping range of temperatures from the thermal window of each species.

\section{MATERIALS AND METHODS}

\section{Animal collection}

Juvenile Boreogadus saida were caught at $120 \mathrm{~m}$ depth in the inner part of the Kongsfjord on a polar night trawl on 17 January $2013\left(78.97^{\circ} \mathrm{N}, 12.51^{\circ} \mathrm{E}\right)$. 
Subsequently, the animals were kept in facilities of the Tromsø Aquaculture Research Station, in Kårvik, Norway. Juvenile Gadus morhua were caught in various locations of western Svalbard between 26 and 29 August 2013 on a cruise of the RV 'Heincke' in Rijpfjorden $\left(80.15^{\circ} \mathrm{N}, 22.12^{\circ} \mathrm{E}\right)$, Hinlopenstretet $\left(79.30^{\circ} \mathrm{N}\right.$, $\left.18.57^{\circ} \mathrm{E}\right)$ and Forlandsundet $\left(78.54^{\circ} \mathrm{N}, 11.3^{\circ} \mathrm{E}\right)$. A fish lift combined with a pelagic mid-water trawl was used to catch the animals (Holst \& McDonald 2000). Further information on the cruise is available at http:// doi.pangaea.de/10.1594/PANGAEA.824703. Specimens of both species were transported to the Alfred Wegener Institute in Bremerhaven, Germany, and kept in aquaria at a water temperature of $5^{\circ} \mathrm{C}$ in a recirculating seawater system prior to the start of the incubation.

\section{Incubation}

Experiments on B. saida and G. morhua started in June 2013 and June 2014, respectively. B. saida and G. morhua were incubated at $0,3,6$ and $8^{\circ} \mathrm{C}$ and at 3 , 8,12 and $16^{\circ} \mathrm{C}$, respectively. $\mathrm{pCO}_{2}$ was either $374-$ $515 \mu$ atm (control $\mathrm{CO}_{2}$ ) or 852-1416 $\mu$ atm (high $\mathrm{CO}_{2}$ ) in a full factorial approach with a group size of 12 animals treatment ${ }^{-1}$, resulting in a sample size of 96 animals for each species. Animals were transferred into individual tanks (height: $35 \mathrm{~cm}$, diameter: $30 \mathrm{~cm}$, volume: $\sim 24 \mathrm{l}$ with a flow-through of $\sim 500 \mathrm{ml} \mathrm{min}^{-1}$ ) and randomly distributed among treatment groups. The animals were kept separately in order to enable quantification of feed consumption of each individual, which was published separately (Kunz et al. 2016). Water supply occurred through a re-circulating aquarium system with a total volume of $10 \mathrm{~m}^{3}$. The seawater for the system was collected in 'Tiefe Rinne', close to Heligoland (Helgoland), Germany, in the North Sea. Adequate water quality was ensured through nitrification filters, UV-sterilizers and protein skimmers, and the nitrate concentration was kept at $<50 \mathrm{mg} \mathrm{l}^{-1}$ at all times. Temperature was adjusted in 4 temperature-controlled rooms (1 room for each temperature treatment) by a maximum change of $2^{\circ} \mathrm{C} \mathrm{d}^{-1}$ for each group, starting from $5^{\circ} \mathrm{C}$. $\mathrm{pCO}_{2}$ in high- $\mathrm{CO}_{2}$ groups was increased within $1 \mathrm{~d}$ after the temperatures were adjusted. The incubation period started after the desired temperature and $\mathrm{CO}_{2}$ condition had been reached for each treatment group. The animals were fed ad libitum with a commercial pellet food (Amber Neptun, Skretting) every fourth day. Day/night cycle was 12:12 h, with lights on at 08:00 h. Oxygen concentration in fish tanks was measured occasionally throughout the incubation period and was always found to be $\sim 100 \%$. Apart from temperature, room conditions were kept as similar as possible, with similarly dimmed light and a small distance between shelves containing the tanks with different $\mathrm{CO}_{2}$-treatments $(\sim 1 \mathrm{~m})$. Opaque walls of the tanks shielded external stimuli effectively, and activities inside the rooms were kept to a minimum. Behavioural experiments were conducted $6 \mathrm{wk}$ after onset of the incubation and lasted $8 \mathrm{~d}$ in total. Length and weight of each animal were measured at the beginning of the incubation and $1 \mathrm{~d}$ after the end of the behavioural experiments. Mean lengths and weights $( \pm \mathrm{SD})$ of individuals in each treatment group and species are available in Tables S1 \& S2 in the Supplement at www.int-res.com/articles/suppl/m571p183_ supp.pdf. One out of 96 B. saida and 8 out of 96 G. morhua died during the incubation period for unknown reasons. The 8 casualties among G. morhua occurred in 5 different treatment groups at all temperatures as well as at control and high $\mathrm{pCO}_{2}$, with no more than 2 specimens dying per treatment group. These mortalities were thus considered independent of the treatment conditions. A representative image of the incubation system of one treatment group is provided in Fig. S1 in the Supplement.

\section{$\mathrm{CO}_{2}$ and carbonate chemistry}

Seawater was aerated with an air/ $\mathrm{CO}_{2}$ mixture from a gas-mixing pump (HTK) before flowing into the tanks holding the animals. Temperature, salinity, dissolved inorganic carbon and $\mathrm{pH}_{\text {tot }}$ were determined at least once weekly in order to calculate the seawater carbonate parameters. Means were calculated for each week; Tables S1 \& S2 list the means \pm SD over the whole incubation period for each treatment group and species. Detailed methodological information and the raw data are provided at https://doi. pangaea.de/10.1594/PANGAEA.866369.

\section{Behavioural testing}

Spontaneous activity

Spontaneous activity was tested $2 \mathrm{~d}$ after feeding. A camera was installed in the centre above the housing tank of an animal next to a white LED lamp for better illumination. Recordings were started manually 10 min after camera installation and illumination. The recordings lasted for at least $10 \mathrm{~min}$, and the last 
5 min were used for quantification of spontaneous activity. For post-processing of the video, a grid was placed centrally over the tank, dividing it into 4 equally sized rectangles using the software packages Image J and Dartfish ${ }^{\circledR}$. The frequency of grid lines crossed was counted for each individual within a 5 min period of recording. A crossing was counted when the whole head of an animal crossed a grid line (ending right before the pectoral fins). For each animal, the total number of grid lines crossed was divided by 5 to obtain the number of lines crossed $\mathrm{min}^{-1}$. Operator-controlled analysis of behaviour was performed in a randomized order for each species without knowing animal or treatment to avoid any observer bias. Videos were recorded throughout the whole day, whereby only animals of one temperature treatment were observed per day. The sequence of video recordings alternated between the $2 \mathrm{CO}_{2}$ treatments to compensate for possible daytime-related differences in activity. In total, data from 94 B. saida and 87 G. morhua were used to quantify spontaneous activity. Video recordings for 2 animals had to be discarded for technical reasons.

\section{Behavioural laterality}

On the same day, after recording activity, each fish was transferred into a $125 \times 50 \mathrm{~cm}$ aquarium containing a 2-sided T-maze, similar to the maze used by Domenici et al. (2012), to investigate combined effects of temperature and $\mathrm{CO}_{2}$ on behavioural laterality via a detour test. The opaque maze, with a runway length of $70 \mathrm{~cm}$ and width of $8 \mathrm{~cm}$, was placed in the centre of the aquarium. Perpendicular to each of the maze's ends was a dark grey, opaque barrier with a length of $25 \mathrm{~cm}$ leaving a gap of $5.5 \mathrm{~cm}$ on each side so that the animal could leave the maze on either left or right (see Fig. S2 in the Supplement for a scheme of the setup). The sides of the aquarium were shielded with a dark grey cover. The aquarium was filled with $10 \mathrm{~cm}$ of seawater according to the test animal's treatment conditions. After an acclimation period of $10 \mathrm{~min}$, the animal was gently encouraged to swim through the maze by approaching it from behind with a meshed plastic slide until the animal reached the end of the runway where it escaped to the left or to the right. The side on which the individual left the maze was noted. This procedure was repeated 14 times for each fish, whereby the swimming direction through the chamber was reversed after each trial to compensate for the potentially disturbing influence of the fish's orientation towards existing room-related structures.
Absolute and relative laterality indices were calculated as described by Domenici et al. (2012). Absolute laterality quantifies the preference of an animal for one side over the other; thus an animal that turned to the same side every time was allocated an absolute laterality index of 100. In contrast, the relative laterality index takes the side preference of each animal into account. An animal that turned to the left every time was allocated a relative laterality index of -100 and an animal that turned to the right every time was assigned a relative laterality index of +100 . All trials were conducted by the same experimenter and lasted about $10 \mathrm{~min}$ for each animal. In total, data from 95 B. saida and 88 G. morhua were tested for behavioural laterality.

\section{Statistical analysis}

Spontaneous activity and absolute and relative laterality were analysed by an ordinary 2-way ANOVA to test for significant effects of temperature, $\mathrm{CO}_{2}$ and possible interactions of these 2 factors. Normality of each group was investigated via D'Agostino and Pearson omnibus normality tests and the homogeneity of variances via a Brown-Forsythe test with $\alpha=0.05$. A significant deviation from a normal distribution was detected in 3 out of 48 groups tested (B. saida: spontaneous activity at $8^{\circ} \mathrm{C}$ and high $\mathrm{pCO}_{2}$; absolute laterality at $6^{\circ} \mathrm{C}$ and low $\mathrm{pCO}_{2}$. G. morhua: spontaneous activity at $8^{\circ} \mathrm{C}$ and high $\mathrm{pCO}_{2}$ ). However, using an $\alpha$ of 0.05 sets the chance of a false positive Type 1 error of each normality test to $5 \%$, which may account for the deviation from normality in those 3 out of 48 tested groups. Furthermore, in 2 out of 3 cases, the observed violation of normality was caused by a single animal, and an exclusion of these animals did not lead to disappearance of the observed significant findings. We thus concluded that it is still acceptable to use the 2way ANOVA under these conditions. A coefficient of variation $(\mathrm{CV})$ was determined for each treatment group of spontaneous activity data by calculating the ratio of standard deviation and mean values, and the difference between the 2 species was analysed using a 2-sided Mann-Whitney test $(\alpha=0.05)$. Correlation between animal length and spontaneous activity was tested with a 2-tailed non-parametric Spearman rtest. The $\mathrm{CO}_{2}$ effect on side preference on a population level and a possible $\mathrm{CO}_{2}$-induced change from a nonrandom to a random distribution of left and right turns were tested for each species by pooling relative laterality data of all temperatures in accordance to control or high $\mathrm{pCO}_{2}$, as we had not detected a significant 
temperature effect on behavioural laterality in either B. saida or G. morhua. Subsequently, 2-sided 1-sample $t$-tests were conducted $(\alpha=0.05)$ for each $\mathrm{CO}_{2}$ treatment of each species testing for significant differences from the hypothetical mean of 0 . Deviation from a random binomial distribution was tested for via a log likelihood ratio goodness of fit test (G-test) using the software 'R' (v. 3.2.3) and the R-package 'DescTools'. GraphPad Prism ${ }^{\circledR} 6$ was used for all other statistical tests and for generation of figures.

\section{RESULTS}

\section{Spontaneous activity}

Spontaneous activity of Boreogadus saida increased significantly with rising ambient temperature between 0 and $8^{\circ} \mathrm{C}\left(\mathrm{p}<0.001, F_{3,86}=7.064\right.$, Fig. $\left.1 \mathrm{~A}\right)$. No significant difference in spontaneous activity of $B$. saida was detected between control and high $\mathrm{CO}_{2}$ concentrations $\left(\mathrm{p}=0.0700, F_{1,86}=3.368\right)$. In contrast, spontaneous activity of Gadus morhua did not significantly depend on temperature $\left(\mathrm{p}=0.3172, F_{3,79}=1.195\right.$, Fig. 1B) or $\mathrm{CO}_{2}$ concentration $\left(\mathrm{p}=0.5024, F_{1,79}=\right.$ 0.4540). G. morhua displayed a non-significant trend towards greater mean activity with increasing tem- perature which was strong between 3 and $8^{\circ}$ but levelled off at higher temperature and even decreased in the group at $16^{\circ} \mathrm{C}$ under normal $\mathrm{CO}_{2}$ levels. A significant interaction between temperature and $\mathrm{CO}_{2}$-related effects was not detected in either species (all $\mathrm{p}>0.05$ ). The CV of spontaneous activity of G. morhua was significantly higher than the CV of $B$. saida ( $p<0.001$, Fig. 1C). Spontaneous activity was not significantly correlated with body length in either species ( $p>0.05)$.

\section{Behavioural laterality}

Absolute laterality of $B$. saida was significantly reduced by $\mathrm{CO}_{2}\left(\mathrm{p}<0.01, F_{1,87}=7.152\right.$, Fig. $\left.2 \mathrm{~A}\right)$, but was not affected by temperature $\left(\mathrm{p}=0.2156, F_{3,87}=1.518\right)$. Also, in this species, relative laterality was dependent on $\mathrm{CO}_{2}\left(\mathrm{p}<0.01, F_{1,87}=10.26\right.$, Fig. $\left.2 \mathrm{C}\right)$, but not on temperature $\left(\mathrm{p}=0.7020, F_{3,87}=0.4728\right)$, with a shift from left to right orientation under increased $\mathrm{CO}_{2}$ concentrations. Side preference of $B$. saida was significantly left biased under control $\mathrm{CO}_{2}(\mathrm{p}<0.05, t=$ 2.242 , df $=47$ ), significantly right biased under high $\mathrm{CO}_{2}(\mathrm{p}<0.05, t=2.260, \mathrm{df}=46)$ and significantly differed from a random binomial distribution under both $\mathrm{CO}_{2}$ conditions $\left(\mathrm{p}<0.001, G=13.761, \chi^{2} \mathrm{df}=1\right.$ for low $\mathrm{pCO}_{2}$ and $\mathrm{p}<0.01, G=7.0399, \chi^{2} \mathrm{df}=1$ for high $\mathrm{pCO}_{2}$ ).
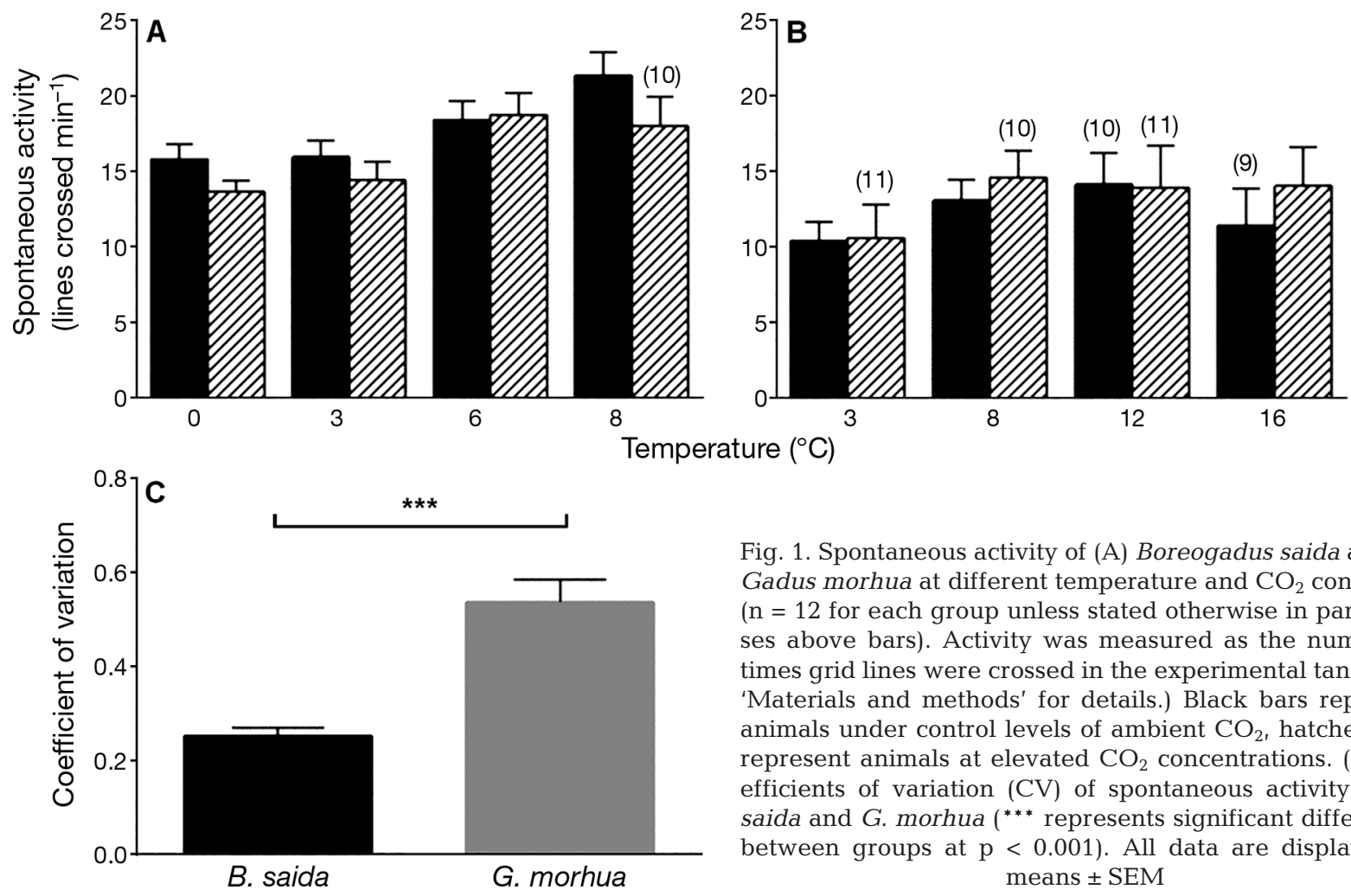

Fig. 1. Spontaneous activity of (A) Boreogadus saida and (B) Gadus morhua at different temperature and $\mathrm{CO}_{2}$ conditions ( $\mathrm{n}=12$ for each group unless stated otherwise in parentheses above bars). Activity was measured as the number of times grid lines were crossed in the experimental tanks (see 'Materials and methods' for details.) Black bars represent animals under control levels of ambient $\mathrm{CO}_{2}$, hatched bars represent animals at elevated $\mathrm{CO}_{2}$ concentrations. (C) Coefficients of variation (CV) of spontaneous activity for $B$. saida and G. morhua ( ${ }^{* * *}$ represents significant differences between groups at $\mathrm{p}<0.001)$. All data are displayed as means \pm SEM 

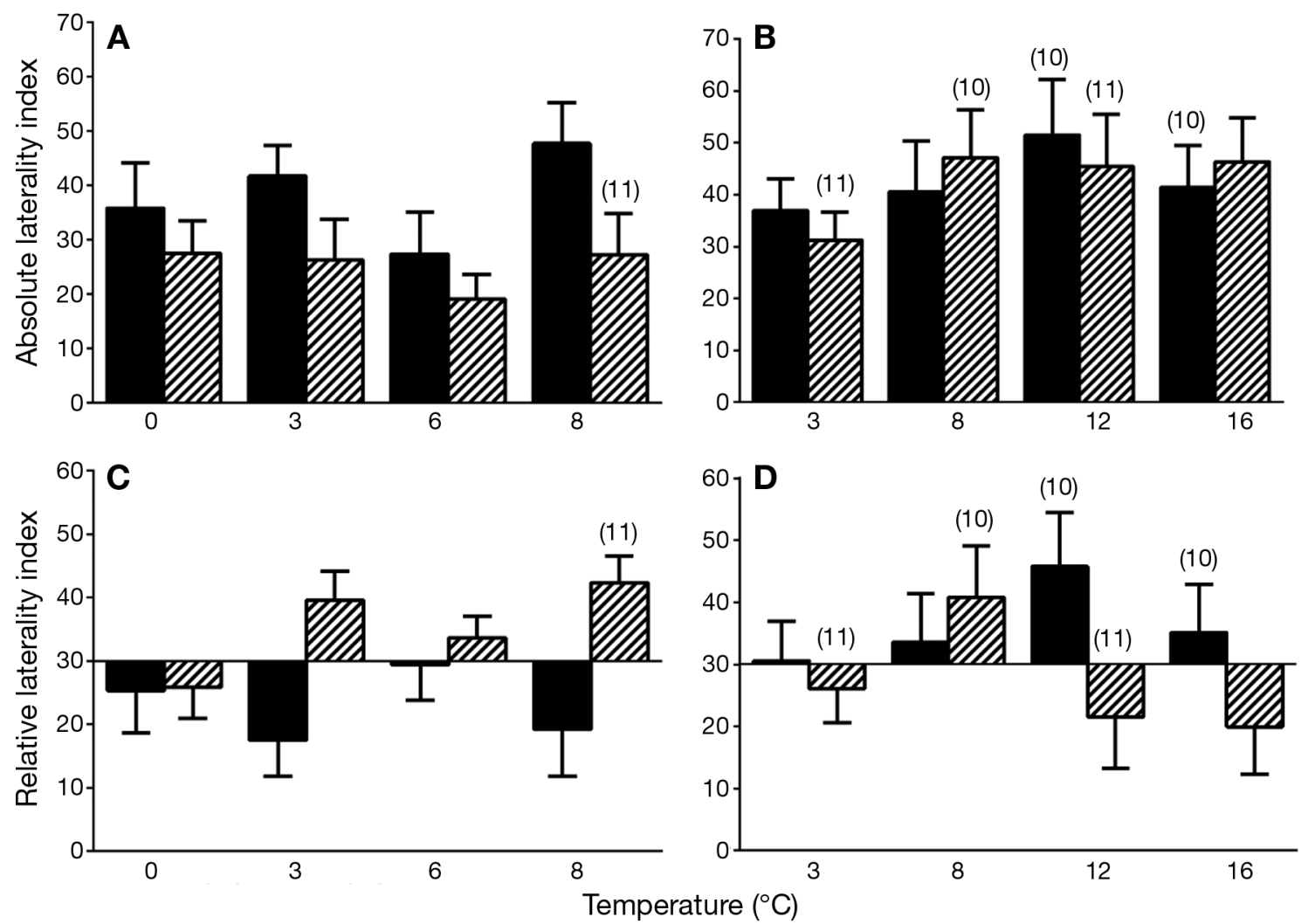

Fig. 2. Absolute laterality index of (A) Boreogadus saida and (B) Gadus morhua and relative laterality index of (C) B. saida and (D) G. morhua at different temperature and $\mathrm{CO}_{2}$ conditions ( $\mathrm{n}=12$ for each group unless stated otherwise in parentheses above bars). Details of laterality indices are given in the 'Materials and methods'. Black bars represent animals under control; hatched bars represent animals at elevated $\mathrm{CO}_{2}$ concentrations. Data are displayed as means \pm SEM

In G. morhua, absolute laterality was not affected by $\mathrm{CO}_{2}\left(\mathrm{p}=0.9949, F_{1,80}=4.086 \times 10^{-5}\right.$, Fig. $\left.2 \mathrm{~B}\right)$ or temperature $\left(\mathrm{p}=0.3966, F_{3,80}=1.002\right)$. Relative laterality also did not significantly depend on $\mathrm{CO}_{2}$ or temperature $\left(\mathrm{p}=0.0913, F_{1,80}=2.920\right.$ and $\mathrm{p}=0.5375, F_{3,80}=$ 0.7293, respectively, Fig. 2D). G. morhua did not exhibit a significant side preference under control or under high $\mathrm{CO}_{2}$ conditions $(\mathrm{p}=0.1272, t=1.556, \mathrm{df}=$ 43 and $\mathrm{p}=0.3792, t=0.8886, \mathrm{df}=43$, respectively). The side preference differed significantly from a binomial random distribution under low, but not quite under high $\mathrm{CO}_{2}$ conditions ( $\mathrm{p}<0.01, G=8.4349, \chi^{2} \mathrm{df}$ $=1$ and $\mathrm{p}=0.09, G=2.8659, \chi^{2} \mathrm{df}=1$, respectively). In both species, no interactive effects were detected between $\mathrm{CO}_{2}$ and temperature effects on absolute and relative laterality (all $\mathrm{p}>0.05$ ).

\section{DISCUSSION}

This is the first study analyzing and comparing the combined effects of $\mathrm{CO}_{2}$ and temperature on the behaviour of 2 gadid fish species, one polar and cold adapted (Boreogadus saida), the other (Gadus morhua) temperate and invasive to the high polar environments due to global warming. We demonstrated that the behavioural vulnerability of fish, even if they are related, may be species-dependent in response to temperature and $\mathrm{CO}_{2}$.

While we observed a significant influence of temperature on spontaneous activity of $B$. saida, no such significance was detected in G. morhua. However, in the latter, a possible temperature effect may have been masked by high inter-individual variability, which was significantly more pronounced in G. morhua than in B. saida. We found no $\mathrm{CO}_{2}$-related effect on the spontaneous activity of $B$. saida and G. morhua, in contrast to strong alterations that were observed in tropical cardinalfish (Apogon cyanosoma and Cheilodipterus quinquelineatus) and damselfish (Pomacentrus wardi) (Munday et al. 2010, 2014), which either showed an increase or a decrease in activity in response to elevated $\mathrm{pCO}_{2}$ as predicted for future OA scenarios. However, $\mathrm{CO}_{2}$-effects on swimming behaviour of fish appear to be strongly species-dependent, and our results are consistent with findings of several 
studies that observed largely resilient routine swimming activity and kinematics particularly in temperate species (including G. morhua larvae) (Maneja et al. 2013, 2015, Sundin \& Jutfelt 2016), but also in tropical species (Nowicki et al. 2012, Bignami et al. 2013 , 2014). As our study was conducted with juvenile specimens of $G$. morhua, it can be concluded that swimming behaviour at least in this species appears to be robust to an increase in environmental $\mathrm{CO}_{2}$ across different life stages.

Interestingly, the effect of $\mathrm{CO}_{2}$ on laterality was different in B. saida and G. morhua. In B. saida, absolute lateralization was significantly reduced and paralleled by a shift from left to right lateralization, whereas in G. morhua, we found no changes in absolute lateralization or side preference. These results conform with recent experiments on temperate fish species, that found a $\mathrm{CO}_{2}$-induced reduction of absolute laterality in three-spined stickleback Gasterosteus aculeatus (Jutfelt et al. 2013, Lai et al. 2015), but not in wrasse Ctenolabrus rupestris or in juvenile G. morhua of similar age compared to the specimens in our study (Jutfelt \& Hedgärde 2015, Sundin \& Jutfelt 2016). Contrary to findings in Pomacentrus wardi (Domenici et al. 2014), we did not detect any interaction of temperature- and $\mathrm{CO}_{2}-$ related effects on behavioural laterality. However, potential interactive effects of $\mathrm{CO}_{2}$ and temperature on the relative laterality of G. morhua may have been missed because of low statistical power resulting from a relatively small sample size. At 3,12 and $16^{\circ} \mathrm{C}$, there was a $\mathrm{CO}_{2}$-induced trend from right to left lateralization in G. morhua, with the opposite at $8^{\circ} \mathrm{C}$, and we suggest this to be the main reason why the turning directions of G. morhua were not significantly different from a random binomial distribution at high $\mathrm{CO}_{2}$. Inter-individual variability of behavioural lateralization is by definition very high, and one must thus be quite cautious with interpretation of these findings. Based on our results, the possibility of interactive effects on the behaviour of $G$. morhua should not be strictly ruled out. Furthermore, for changes in absolute and relative laterality, high inter-individual variability and low effect sizes may have given rise to potential type I errors, which must be considered when comparing differences in $\mathrm{CO}_{2}$ effects between B. saida and G. morhua. A definitive answer to these issues requires further experimental investigation.

Domenici et al. (2014) found a $\mathrm{CO}_{2}$-induced shift in turning preference from right to left, which was interpreted as a change in task processing from the left to the right brain hemisphere. Across taxa, the right brain hemisphere is associated with stress-related endocrine responses and reactive behavioural patterns (Rogers 2010). In humans, the right brain hemisphere is the predominant driver of the pituitaryadrenal axis and of sympathetic cardiac control (Wittling \& Pflüger 1990, Wittling et al. 1998). In contrast, the left brain hemisphere is associated with the execution of routine behaviour (Rogers 2010). A shift in laterality from right to left preference under future OA scenarios as observed by Domenici et al. (2014) would thus indicate a shift in the stress-related cognitive state of the fish, i.e. a $\mathrm{CO}_{2}$-induced shift from a low to a high stress level. Those explanations (inverted function or changing stress level) may not be mutually exclusive, as Hamilton et al. (2014) found a $\mathrm{CO}_{2}$ induced increase of anxiety in rockfish, which could be an indication for a shift to a more active right brain hemisphere. In the study of Hamilton et al. (2014), the mentioned increase in anxiety was related to altered $\mathrm{GABA}_{\mathrm{A}}$-receptor functioning. Speculatively bringing these hypotheses together, an inversion of the $\mathrm{GABA}_{\mathrm{A}}$-receptor function could also be the cause of a shift in brain hemispherical usage which could then be responsible for the shift in side preference.

The question arises why the shift in side preference was opposite in B. saida. Hemispheric laterality is generated during ontogenesis and can be inversed, as shown in domestic chicken by Rogers (1990). This could also be the case for $B$. saida; thus, our findings might still have the same implications as in coral reef fishes. However, this explanation remains speculative, and its verification requires further exploration. The $\mathrm{CO}_{2}$-induced reduction in absolute lateralization of $B$. saida may indicate reduced fitness under future OA scenarios, as the degree of lateralization may correlate with other behavioural parameters such as efficiency of predator avoidance (Dadda et al. 2010). However, predictions about the ecological consequences of our findings need to be made with care, as the animals in our study were kept separate from each other. Furthermore, the sudden availability of more space during laterality tests may have had an unknown effect on the observed outcome. It cannot be excluded that the fish may have behaved differently if they had been incubated under more natural conditions in schooling groups with social hierarchies. Nevertheless, both species were treated similarly and thus comparison of temperature and $\mathrm{CO}_{2}$ effects between these species remains meaningful.

Overall, elevated $\mathrm{CO}_{2}$ levels may affect some behavioural patterns of cold-adapted teleosts, but our findings also indicate species-specific differences in behavioural resilience to OA. Our results are similar 
to those obtained in 3 other studies on temperate fish species. A significant $\mathrm{CO}_{2}$ effect on behaviour, including behavioural laterality and activity, was found in three-spined stickleback, but again, not in temperate Atlantic cod, indicating a reduced vulnerability of behaviour in this species to an increase in environmental $\mathrm{CO}_{2}$ (Jutfelt et al. 2013, Jutfelt \& Hedgärde 2013, 2015). This may be an adaptive trait reflecting its demersal mode of life and repeated exposure to hypoxia and hypercapnic water layers (Neuenfeldt et al. 2009). Due to preadaptation to different environments and levels of variability, the degree of alterations of behaviour under increased $\mathrm{pCO}_{2}$ may vary strongly between species. The mechanisms causing the disturbance of behaviours may include accumulation of bicarbonate in the body fluids (Nilsson et al. 2012) which results from acidbase regulation compensating for $\mathrm{CO}_{2}$-induced acidification (Ishimatsu et al. 2008). The physiological systems supporting behaviour to be insensitive to elevated $\mathrm{CO}_{2}$ (and possibly, bicarbonate accumulation) remain to be investigated. Such understanding will be crucial for projecting teleost resilience under future $\mathrm{CO}_{2}$ scenarios (Wittmann \& Pörtner 2013). As discussed above, it may be possible that $\mathrm{CO}_{2}$ effects on the behaviour of $G$. morhua are dependent on the environmental temperature. This would make Atlantic cod a useful species for elaboration of the physiological mechanisms determining behavioural vulnerability or resistance of fish species in a future, more acidified ocean.

In summary, this study indicates that the behaviour of $B$. saida is more vulnerable to future OA than the behaviour of G. morhua. We did not observe significant temperature-driven modulation in the extent of behavioural alteration; however, in G. morhua, interactive effects of temperature and $\mathrm{CO}_{2}$ might have been missed due to the small size of treatment groups. Nevertheless, the temperature-independent reduction in the behavioural laterality of $B$. saida may indicate reduced fitness of this species in a high $\mathrm{CO}_{2}$ world, which might place it at a disadvantage in competitive and predator-prey interactions with G. morhua in the waters around Svalbard. Future warming of the area can lead to an increasing population size of G. morhua and a further northward shift of species distribution areas (Perry et al. 2005). In a warmer, more acidified, open ocean, G. morhua may outcompete $B$. saida in the long term. However, the potential of species to acclimate or adapt their behaviour under combined OA and OW over generations has received little attention (Allan et al. 2014) and urgently demands further investigation.
Acknowledgements. We thank Jasmine Nahrgang for providing the specimens of $B$. saida (funded by the Polarisation grant of the Norwegian Research Council, no. 214184/F20), Janina Popp for her contribution to data analysis and Philip Munday for helpful suggestions for the experimental design. Silvia Hardenberg, Sebastian Berger and Guido Krieten helped with the technical realization of the incubation setup and during the incubation period. We also thank Karim Zanaty, Marcel Machnik, Benjamin Matthei, Fredy Vèliz Moraleda, Anette Tillmann, Isabel Ketelsen and Timo Hirse for their contributions to the measurements of $\mathrm{pH}$ and dissolved inorganic carbon. We appreciate the helpful statistical advice of Stephan Frickenhaus and thank Nils Koschnick and Heidrun Windisch for various services they provided throughout the incubation period. This work was funded by the Federal Ministry of Education and Research (BMBF, no. FKZ 03F0655B), Germany. The experiments were conducted in accordance with the ethical standards of the federal state of Bremen, Germany, and were approved under reference number 522-27-11/02-00 (93). The tested animals were used in subsequent experiments that will be published elsewhere and were ultimately sacrificed for organ removal.

\section{LITERATURE CITED}

Allan BJM, Miller GM, McCormick MI, Domenici P, Munday PL (2014) Parental effects improve escape performance of juvenile reef fish in a high- $\mathrm{CO}_{2}$ world. Proc R Soc Lond B Biol Sci 281:20132179

* Beierlein L, Salvigsen O, Schöne BR, Mackensen A, Brey T (2015) The seasonal water temperature cycle in the Arctic Dicksonfjord (Svalbard) during the Holocene Climate Optimum derived from sub-fossil Arctica islandica shells. Holocene 25:1197-1207

* Bignami S, Sponaugle S, Cowen RK (2013) Response to ocean acidification in larvae of a large tropical marine fish, Rachycentron canadum. Glob Change Biol 19:996-1006

Bignami S, Sponaugle S, Cowen RK (2014) Effects of ocean acidification on the larvae of a high-value pelagic fisheries species, mahi-mahi Coryphaena hippurus. Aquat Biol 21:249-260

Cripps IL, Munday PL, McCormick MI (2011) Ocean acidification affects prey detection by a predatory reef fish. PLOS ONE 6:e22736

* Dadda M, Zandonà E, Agrillo C, Bisazza A (2009) The costs of hemispheric specialization in a fish. Proc R Soc Lond B Biol Sci 276:4399-4407

*Dadda M, Koolhaas WH, Domenici P (2010) Behavioural asymmetry affects escape performance in a teleost fish. Biol Lett 6:414-417

Domenici P, Allan B, McCormick MI, Munday PL (2012) Elevated carbon dioxide affects behavioural lateralization in a coral reef fish. Biol Lett 8:78-81

* Domenici P, Allan BJM, Watson SA, McCormick MI, Munday PL (2014) Shifting from right to left: the combined effect of elevated $\mathrm{CO}_{2}$ and temperature on behavioural lateralization in a coral reef fish. PLOS ONE 9:e87969

Drinkwater K (2009) Comparison of the response of Atlantic cod (Gadus morhua) in the high-latitude regions of the North Atlantic during the warm periods of the 1920s1960s and the 1990s-2000s. Deep-Sea Res II 56:2087-2096

* Ferrari MC, Munday PL, Rummer JL, McCormick MI and others (2015) Interactive effects of ocean acidification and rising sea temperatures alter predation rate and predator 
selectivity in reef fish communities. Glob Change Biol 21: 1848-1855

Hamilton TJ, Holcombe A, Tresguerres M (2014) $\mathrm{CO}_{2}-$ induced ocean acidification increases anxiety in rockfish via alteration of $\mathrm{GABA}_{\mathrm{A}}$ receptor functioning. Proc $\mathrm{R}$ Soc Lond B Biol Sci 281:20132509

Heuer RM, Grosell M (2014) Physiological impacts of elevated carbon dioxide and ocean acidification on fish. Am J Physiol Regul Integr Comp Physiol 307:R1061-R1084

Holst JC, McDonald A (2000) FISH-LIFT: a device for sampling live fish with trawls. Fish Res 48:87-91

Hop H, Gjøsæeter H (2013) Polar cod (Boreogadus saida) and capelin (Mallotus villosus) as key species in marine food webs of the Arctic and the Barents Sea. Mar Biol Res 9: 878-894

IPCC (2013) Climate change 2013: the physical science basis. Contribution of Working Group I to the Fifth Assessment Report of the Intergovernmental Panel on Climate Change. Cambridge University Press, Cambridge and New York, NY

Ishimatsu A, Hayashi M, Kikkawa T (2008) Fishes in high$\mathrm{CO}_{2}$ acidified oceans. Mar Ecol Prog Ser 373:295-302

Jutfelt F, Hedgärde M (2013) Atlantic cod actively avoid $\mathrm{CO}_{2}$ and predator odour, even after long-term $\mathrm{CO}_{2}$ exposure. Front Zool 10:81

Jutfelt F, Hedgärde M (2015) Juvenile Atlantic cod behavior appears robust to near-future $\mathrm{CO}_{2}$ levels. Front Zool 12: 11

Jutfelt F, Bresolin de Souza K, Vuylsteke A, Sturve J (2013) Behavioural disturbances in a temperate fish exposed to sustained high- $\mathrm{CO}_{2}$ levels. PLOS ONE 8:e65825

Kunz KL, Frickenhaus S, Hardenberg S, Johansen T and others (2016) New encounters in Arctic waters: a comparison of metabolism and performance of polar cod (Boreogadus saida) and Atlantic cod (Gadus morhua) under ocean acidification and warming. Polar Biol 39:1137-1153

Lai F, Jutfelt F, Nilsson GE (2015) Altered neurotransmitter function in $\mathrm{CO}_{2}$-exposed stickleback (Gasterosteus aculeatus): a temperate model species for ocean acidification research. Conserv Physiol 3:cov018

Maneja RH, Frommel AY, Browman HI, Clemmesen C and others (2013) The swimming kinematics of larval Atlantic cod, Gadus morhua L., are resilient to elevated seawater $\mathrm{pCO}_{2}$. Mar Biol 160:1963-1972

Maneja RH, Frommel AY, Browman HI, Geffen AJ and others (2015) The swimming kinematics and foraging behavior of larval Atlantic herring (Clupea harengus L.) are unaffected by elevated $\mathrm{pCO}_{2}$. J Exp Mar Biol Ecol 466:42-48

Miller GM, Watson SA, Donelson JM, McCormick MI, Munday PL (2012) Parental environment mediates impacts of increased carbon dioxide on a coral reef fish. Nat Clim Chang 2:858-861

Munday PL, Dixson DL, McCormick MI, Meekan M, Ferrari MCO, Chivers DP (2010) Replenishment of fish populations is threatened by ocean acidification. Proc Natl Acad Sci USA 107:12930-12934

Munday P, Pratchett M, Dixson D, Donelson J, Endo GK,

Editorial responsibility: Alejandro Gallego,

Aberdeen, UK
Reynolds A, Knuckey R (2013) Elevated $\mathrm{CO}_{2}$ affects the behavior of an ecologically and economically important coral reef fish. Mar Biol 160:2137-2144

* Munday PL, Cheal AJ, Dixson DL, Rummer JL, Fabricius KE (2014) Behavioural impairment in reef fishes caused by ocean acidification at $\mathrm{CO}_{2}$ seeps. Nat Clim Chang 4: 487-492

Neuenfeldt S, Andersen KH, Hinrichsen HH (2009) Some Atlantic cod Gadus morhua in the Baltic Sea visit hypoxic water briefly but often. J Fish Biol 75:290-294

Nilsson GE, Dixson DL, Domenici P, McCormick MI, Sorensen C, Watson SA, Munday PL (2012) Near-future carbon dioxide levels alter fish behaviour by interfering with neurotransmitter function. Nat Clim Chang 2:201-204

Nowicki JP, Miller GM, Munday PL (2012) Interactive effects of elevated temperature and $\mathrm{CO}_{2}$ on foraging behavior of juvenile coral reef fish. J Exp Mar Biol Ecol 412:46-51

*Perry AL, Low PJ, Ellis JR, Reynolds JD (2005) Climate change and distribution shifts in marine fishes. Science 308:1912-1915

* Renaud P, Berge J, Varpe Ø, Lønne O, Nahrgang J, Ottesen C, Hallanger I (2012) Is the poleward expansion by Atlantic cod and haddock threatening native polar cod, Boreogadus saida? Polar Biol 35:401-412

Rogers LJ (1990) Light input and the reversal of functional lateralization in the chicken brain. Behav Brain Res 38: 211-221

Rogers LJ (2010) Relevance of brain and behavioural lateralization to animal welfare. Appl Anim Behav Sci 127:1-11

* Rogers LJ, Zucca P, Vallortigara G (2004) Advantages of having a lateralized brain. Proc R Soc Lond B Biol Sci 271(Suppl 6):S420-S422

Kundby S, Nakken O (2008) Spatial shifts in spawning habitats of Arcto-Norwegian cod related to multidecadal climate oscillations and climate change. ICES J Mar Sci 65: 953-962

* Sundin J, Jutfelt F (2016) 9-28 d of exposure to elevated $\mathrm{pCO}_{2}$ reduces avoidance of predator odour but had no effect on behavioural lateralization or swimming activity in a temperate wrasse (Ctenolabrus rupestris). ICES J Mar Sci 73:620-632

Vallortigara G, Rogers LJ (2005) Survival with an asymmetrical brain: advantages and disadvantages of cerebral lateralization. Behav Brain Sci 28:575-589

*Welch MJ, Watson SA, Welsh JQ, McCormick MI, Munday PL (2014) Effects of elevated $\mathrm{CO}_{2}$ on fish behaviour undiminished by transgenerational acclimation. Nat Clim Chang 4:1086-1089

*Wittling W, Pflüger M (1990) Neuroendocrine hemisphere asymmetries: salivary cortisol secretion during lateralized viewing of emotion-related and neutral films. Brain Cogn 14:243-265

Wittling W, Block A, Schweiger E, Genzel S (1998) Hemisphere asymmetry in sympathetic control of the human myocardium. Brain Cogn 38:17-35

*Wittmann AC, Pörtner HO (2013) Sensitivities of extant animal taxa to ocean acidification. Nat Clim Chang 3:995-1001

Submitted: June 6, 2016; Accepted: March 24, 2017

Proofs received from author(s): April 20, 2017 